\title{
Understanding Middle Students' Beliefs About Knowledge and Learning Using a Multidimensional Paradigm
}

\author{
Marlene Schommer-Aikins, Wei-Cheng Mau, Susan Brookhart, Rosetta Hutter
}

\begin{abstract}
Recent theory (Schommer, 1990) suggests that personal epistemology is multidimensional. The multidimensional epistemology structure with middle school students was tested in this study. Over 1,200 students in Grades 7 and 8 completed an epistemological belief questionnaire. Prior theory, developed with college students, suggested 4 epistemological belief factors: Ability to Learn, Structure of Knowledge, Speed of Learning, and Stability of Knowledge. Confirmatory factor analysis applied to a random half of the sample indicated that a 3-factor model was a good fit to the data. That model was replicated with the second half of the data. Follow-up regression analyses indicated that the more students believed in gradual learning and incremental ability to learn, the higher GPA they earned. Key words: epistemological beliefs, instruction and testing, middle school students
\end{abstract}

Epistemological beliefs, or beliefs about the nature of knowledge and learning, have recently become a focal point of education research. Mounting evidence suggests that those beliefs play an important role in learning (Hofer \& Pintrich, 1997; Kardash \& Scholes, 1996; Schommer, 1998). The effects of epistemological beliefs are complex. Personal epistemology is composed of multiple beliefs and each belief might have a differing effect on learning (Schommer, 1990). For example, the more learners believe that learning happens quickly or not at all, the more poorly they perform on mathematical tasks (Schoenfeld, 1983). The more learners believe that knowledge is unchanging, the more likely they are to misinterpret tentative information (Schommer, 1990). To date, that multidimensional aspect of personal epistemology has been studied only with high school, college, and adult samples. The current study examines middle school students' epistemological beliefs using the multiple-dimension paradigm.

Historically, personal epistemological beliefs have been studied with a unidimensional approach. For example, Perry (1968), the forerunner of epistemological belief research, interviewed and surveyed Harvard University undergraduates. He concluded that undergraduate students enter college thinking knowledge is simple, certain, and handed down by authority. Perry said that by the time they reach their senior year, undergraduates come to believe that knowledge is complex, tentative, and acquired through rea-son and empirical evidence.

Following Perry's (1968) research, Kitchener and King (1981) developed the epistemological conception of reflective judgment-the way in which an individual judges the quality of knowledge is based on the source and certainty of information. Working with college students and adults, those researchers concluded that individuals progress through seven developmental stages of reflective judgment that range from unquestioning acceptance of knowledge to tentative acceptance of knowledge after critical thinking.

Schoenfeld (1983), who worked independently from Perry's (1968) research, studied the mathematical epistemological beliefs of high school students. After analyzing his observations of high school students working with geometry problems, he concluded that many high school students believe 
that mathematicians are born with the abil-ity to do mathematics and mathematical problems should be solved in 12 min or less.

Dweck and Leggett (1988) examined middle school students' beliefs about intelligence. Through interviews, she found that some students believe intelligence is fixed and that the ability to learn is determined at birth. Other students believe intelligence is incremental-the ability to learn can improve over time and experience. After carefully selecting students with similar ability, but different beliefs about intelligence, Dweck and Leggett found that the students who believed in fixed intelligence displayed helpless behav-ior in the face of a difficult academic task. Students who believed in incremental intelligence persisted in effort and varied their study strategies when faced with a difficult task. Ultimately, students who believed in incremental intelligence outperformed students who believed in fixed ability.

Boyes and Chandler (1992) studied adolescents' beliefs about the certainty of knowledge. On the basis of interviews, they concluded that young people move through a developmental sequence of naive realism (knowledge is the mere reflection of what is experienced), to the dogmatism-skepticism axis (believing either everything is absolutely true or nothing is ever true), and finally to postskeptical rationalism (direct access and complete evidence of truth is not a necessary prerequisite for making decisions). The authors hypothesized that some middle school students have begun to experience the roller coaster effects of the dogmatism-skepticism axis. That period of epistemic development manifests itself in familiar adolescent behavior, ranging from the overly devout followers of a peer group to the perpetual skeptic.

Although each area of epistemological belief inquiry has provided insight into the mind, an attempt to synthesize information across the different methods of inquiry resulted in a portrait resembling decoupage. Furthermore, personal epistemology may be far too complex to be captured in a single dimension (Schommer, 1990). To confront that issue, Schommer $(1990,1994)$ developed a theoretical framework for epistemological beliefs according to the synthesis of earlier research. First, she hypothesized that personal epistemology should be conceived as a system of beliefs, that is, personal epistemology is composed of multiple beliefs. In her original thinking, she suggested that at the minimum, five beliefs should be considered: beliefs about knowledge (i.e., the source, certainty, and structure of knowledge) and beliefs about learning (i.e., the speed and control of learning).

Second, Schommer (1994) hypothesized that the multiplicity of epistemological beliefs may be more or less independent. That is, one cannot assume that all the beliefs within an individual's system develop at the same rate. Development in that context indicates the degree to which an epistemological belief supports higher order thinking. For example, less-developed epistemological beliefs accommodate only lower level learning, such as memorizing without concern for comprehension, accepting information without questioning, having strong resistance to change when new evidence is provided, and cramming the night before a test. As an example, individuals who believe strongly that knowledge is organized as isolated bits and pieces report that memorizing lists is their typical approach to learning (Schommer, Crouse, \& Rhodes, 1992). More developed epistemological beliefs support higher order thinking but still can accommodate lower level thinking as the exception to the rule. For example, individuals may believe that much of knowledge is tentative, yet still hold the notion that a small core of knowledge is stable. Those individuals are likely to keep an open mind to new information, yet, at the same time, require substantial evidence to change their views. An element of balance is needed for ultimate development. That is, an extreme view that all knowledge is either changing or never changing could be problematic. Boyes and Chandler's (1992) examples of dogmatism and the perpetual skeptic are explicit examples of an expression of extreme belief in either unchanging or changing knowledge.

Follow-up research has supported Schommer's (1990) basic notions of an epistemological belief system. Working with college students, Schommer (1990) developed a questionnaire to assess beliefs about knowledge and learning. Factor analysis generated four epistemological belief factors: Ability to Learn (ranging from the ability to learn is fixed at birth to the ability to learn is acquired); Structure of 
Knowledge (ranging from knowledge is organized as isolated bits to knowledge is organized as complex, interrelated concepts); Speed of Learning (ranging from learning is quick or not-at-all to learning is gradual); and Stability of Knowledge (ranging from knowledge is unchanging to knowledge is evolving). Furthermore, Schommer (1990) found that students' beliefs within their own system exist at differing levels of development. For example, students can believe that knowledge is absolutely unchanging, yet, at the same time, believe that knowledge is structured in complex interrelationships. The four-factor structure has been replicated with other college students (Dunkle, Schraw, \& Ben-dixen, 1993; Schommer, 1992) and with high school students (Schommer, 1993).

Schommer (1994) theorized that the correlational relationships of epistemological beliefs, as well as their multi-dimensionality, may vary over a life span. Specifically, she hypothesized that early in life, children's personal epistemology will be interrelated and less developed. In the middle years, children and young adults' epistemological beliefs will be differentiated and vary in their level of development. Once adults have reached a degree of expertise in a specific field, their epistemological beliefs will be inte-grated and similar in their level of development.

The focus of this study is middle school students' epistemological belief systems. An underlying assumption in that area of inquiry is that identifying an epistemological belief system is more advantageous than simply combining information from the decoupage of evidence according to unidi-mensional conceptions of personal epistemology. First, using a unidimensional approach provides only a partial picture of an individual's personal epistemology. Essentially, there is important missing information from the unidimensional approach. Second, once a technique has been developed to capture a set of epistemological beliefs, educators are in a better position to understand what may appear to be contradictory behavior or contradictory thinking. For example, one may observe that a student clearly embraces complex solutions to problems, but once a solution is found, the student is resistant to the consideration that other solutions are possible or that the solution may need to change over time. That observation is likely to be characteristic of a student with strong beliefs in complex, certain knowledge. On the other hand, one may notice that a student seeks only simple, single answers, yet is very open to the need to change over time or situation. That circumstance is likely to be characteristic of a student with a strong belief in simple, tentative knowledge. Third, conceptualizing and measuring a system of epistemological beliefs will deepen our understanding of the complexity of personal epistemology.

Although middle school students' personal epistemology has been examined with a unidimensional approach (Boyes \& Chandler, 1992; Dweck \& Leggett, 1988), this study provides a broad perspective by pursuing the investigation of middle school students' epistemological belief systems. We addressed two questions in this research: (a) Is the four-factor structure found with high school and college students also evident in middle school students' epistemological beliefs? (b) If there is evidence of multidimensionality, are middle school students' epistemological beliefs correlated with each other, indicating a less differentiated epistemological belief system compared with older students?

\section{Method}

Participants

Participants in this study included 1,269 students from two middle schools in the Midwest. Gender (boys, $\mathrm{n}=587$; girls, $\mathrm{n}=657$; not reported, $\mathrm{n}=25$ ) and grade (seventh, $\mathrm{n}=619$; eighth, $\mathrm{n}=644$; not reported, $n=6$ ) were approximately equal in representation. Students were predominately Caucasian (86\% European American, 5\% African American, 5\% Hispanic American, 3\% Asian American, 3\% Native American) and middle class (23\% received free lunch).

\section{Materials}

An epistemological belief questionnaire (EB scale) was constructed using high school and college versions of an epistemological belief instrument (Schommer, 1990, 1993, 1998) as a guide. The 
epistemological questionnaire was revised to have fewer items and, if necessary, simpler expression of ideas to be more appropriate for middle school students.

In a previous study with 97 college students, factor analysis of a 31-item questionnaire, according to Schommer's (1990) original questionnaire, generated a four-factor structure similar to that found with the 63-item questionnaire (Mori, 1996). Those items initially were pilot tested with 100 middle school students in the nearby city in which the participants in this study attended school. As the students completed the questionnaire, we encouraged them to report when the items did not make sense. Students also were asked to write notes or to place a check mark next to items that were difficult to understand. Middle school teachers also examined the epistemological items to determine the appropriateness of language and comprehensibility for middle school students.

We constructed a 30-item epistemological questionnaire on the basis of our screening process. Only one item was reworded substantially to simplify expression of thought. "Truth never changes" was revised to "I can depend on the facts written in my school books for the rest of my life." One item that was confusing to students was dropped to create an even-numbered questionnaire.

Students responded on a Likert-type scale ranging from 1 (strongly disagree) to 5 (strongly agree). Statements were written to assess students' beliefs about Ability to Learn ("Some people are just born smart, others are born dumb"), Structure of Knowledge ("Most words have one clear meaning"), Speed of Learning ("Learning something really well takes a long time"), and Stability of Knowledge ("Scientists can get to the truth if they just keep searching for it"). Items were written such that a less epistemologically developed individual would agree with about half the items and disagree with the remaining ones (see Table 1). Order of items was randomized. The EB scale was administered in students classroom by teachers. Furthermore, permission was granted from one school to obtain student GPA for group analysis.

\section{Procedure}

Our strategy in this study was to obtain cooperation from teachers and students. In both schools, the principal and teachers had a basic understanding of the research process. Their understanding facilitated the teacher training within the school to help administer the epistemological questionnaire. Furthermore, circumstances made the assessment of students' beliefs relevant to the district. The schools in this Midwestern state were required to administer yearly assessments of topics, such as reading comprehension and mathematical problem solving. Students were advised throughout the school year that the ratings should be taken seriously. District assessments were administered over 2 weeks to avert a fatigue effect. The epistemological ques-tionnaire was included among the assessments. The teachers and principal perceived the epistemological assessment to be important beyond a contribution to research because the local district also was requiring assessment of students' attitudes toward learning. The first author of this study provided a report to the schools in return for their cooperation.

We provided the teachers with written and oral instructions to administer the questionnaire under controlled conditions. Students were instructed to do their own work. Furthermore, students were assured that there were no right or wrong answers, rather, that this particular assessment was meant to give them an opportunity to voice their beliefs about learning and knowledge. The teachers had a quiet activity ready for students who finished early so they would not disrupt the students who continued to answer questions. 
Table 1. Hypothesized Four-Factor Model According to

Previous Research With College and High School Students

Epistemological belief

Valence

Item

Ability to Learn

$+\quad$ Some people are just born smart, others are born dumb.

- What students learn from a textbook depends on how they study it.

- A class in study skills would probably help slow learners.

$+\quad$ Working hard on a difficult problem pays off only for the really smart students.

$+\quad$ An expert is someone who is born smart in something.

$+\quad$ The really smart students don't have to work hard to do well in school.

$+\quad$ Students who are average in school will remain "average" for the rest of their lives.

- $\quad$ Getting ahead takes a lot of work.

- $\quad$ The knowledge of how to study is usually learned as we grow older.

Speed of Learning

- If I can't understand something right away, I will keep on trying.

$+\quad$ You cannot learn anything more from a textbook by reading it twice.

- $\quad$ Learning something really well takes a long time.

+ Successful students understand things quickly.

$+\quad$ If I cannot understand something quickly, it usually means I will never understand it.

+ If I am ever going to be able to understand something, it will make sense to me the first time I hear it.

- If I find the time to re-read a textbook chapter, I get a lot more out if it the second time.

Stability of Knowledge

$+\quad$ I can depend on facts written in my school books for the rest of my life.

$+\quad$ Scientists can get to the truth if they just keep searching for it.

- Today's facts may be tomorrow's fiction.

$+\quad$ If scientists try hard enough, they can find the truth to almost everything.

Structure of Knowledge

$+\quad$ It is hard to learn from a textbook unless you start at the beginning and learn one chapter at a time.

$+\quad$ The best thing about a science course is that most prob-lems have only one right answer.

+ You will get mixed up if you try to combine new ideas in a textbook with what you already know.

- $\quad$ I like it when experts disagree.

$+\quad$ Being a good student generally involves memorizing facts.

- $\quad$ Thinking about what a textbook says is more important than memorizing what a textbook says.

$+\quad$ I really do not like listening to teachers who cannot seem to make up their minds as to what they really believe.

$+\quad$ Most words have one clear meaning.

- $\quad$ To me, studying means getting the big ideas from the textbook, rather than the details.

Note. Positive and negative valences indicate the presumed agreement or disagreement to the item from the perspective of a less epistemologically developed student. 


\section{Results}

The purpose of our analyses was to determine whether middle school students' epistemological beliefs reflect the same four-factor structure found for high school and college students. We examined the four-factor structure with the confirmatory factor analytic (CFA) approach via the struc-tural equation modeling (SEM) technique. We used the AMOS (1997) computer program for the analyses because of its ability to handle missing data. Three percent of the data were missing, so we substituted group means. We hypothesized the 30 -item scale to represent the four epistemological belief factors. Each item was hypothesized to load on only one of the four factors.

The hypothesized four-factor model, which was based on previous research with high school and college students (Schommer, 1990, 1992, 1993), is reported in Table 1. The analysis for this study was focused on determining whether the items measured unique factors and, if so, whether the epistemological factors were correlated. The data set was divided randomly into two halves $(n=650$ and $n=619$ ). Preliminary analyses were done with half of the data. Once a model was identified, it was replicated with the reserved half of the data.

Chi-square goodness-of-fit index is a typical method for evaluating models. However, the chisquare statistic is sen-sitive to sample size. That is, even if the discrepancy between the proposed model and data is small, almost any model will be rejected if the sample size is large. Two common ways to address that problem involve the use of chi-square to degree of freedom ratio and multiple-fit indexes as evaluation criteria. Although a ratio of chi-square to degree of freedom ratio $\left(X^{2}: d f\right)$ should be close to 1 , a ratio of 2 has been suggested as a reasonable fit (Hatcher, 1994 ). AMOS also provides several useful goodness-of-fit indexes (GFI), comparative fit index (CFI), and root square mean residual (RMR). For GFI and $\mathrm{CFI}$, a value of 1 indicates a perfect fit; a value higher than .90 has been considered a reasonable fit. For RMR, an ideal value is 0 , whereas a value smaller than .05 is considered a reasonable fit.

The $\mathrm{X}^{2}: d f$ ratio for the original hypothesized model was 2.91 , larger than the criterion of 2 . The robust CFI for the hypothesized model was .67 and the G.I. was .87, smaller than the criterion of .90 . The RMR was .088 , greater than the criterion of .05 . All of the measures suggested that the goodness of fit of the four-factor model was less than adequate.

To improve the fit, we removed from the model the items that had small factor loadings and did not correlate with other items. Consequently, the Structure of Knowledge factor was deleted, which led to a substantial improvement in the goodness-of-fit indexes. Figure I depicts the three-factor model according to the sample of middle school students. The $X^{2}: d f$ ratio was reduced to 1.61 ; the CFI and GFI were greater than .90; and RMR was smaller than .05. In summary, those measures indicated that the model was adequate. Table 2 shows the items that were retained, along with their factor loadings. Table 3 shows the zero-order correlations among the items retained in the model.

To further test the integrity of the modified model, we applied the same measurement tests to the reserved split sample. The quality of fit was replicated (see the goodness-of-fit indexes in Table 4).

We tested correlations among factors with zero-order interfactor correlations. Correlations among factors range from -.23 to .81 for the modified model and from $-.27, .96$ for the replicated model (see Table 5). All correlatior were statistically significant $(p<.001)$.

Finally, students' GPAs were regressed on epistemological belief scores to test the predictive value of the epistemological measures. GPAs were available from one school.

To ensure that students with GPA information were not substantially different from the entire sample, we conducted chi-square analyses to compare students with and without GPA information. No significant differences were found for gender (51 \% boys and $49 \%$ girls with GPA; $46 \%$ boys and $54 \%$ girls without GPA) or for grade in school (50\% seventh graders and $50 \%$ eighth graders with GPA; $50 \%$ seventh graders and 50\% eighth graders without GPA). We tested representativeness of beliefs in the GPA sample using a one-way multivariate analysis of variance with availability of GPA as the predictor variable and epistemological belief scores as criterion measures. No significant differences were found (i.e., mean 
scores among students with and without GPA were not different: speed of learning 1.98 versus 2.06; ability to learn 2.10 versus 2.05 ; stability of knowledge 3.83 versus 3.74 ).

Figure 1. The Three-Factor Model According to the Confirmatory Factor Analysis of Middle School Student Data

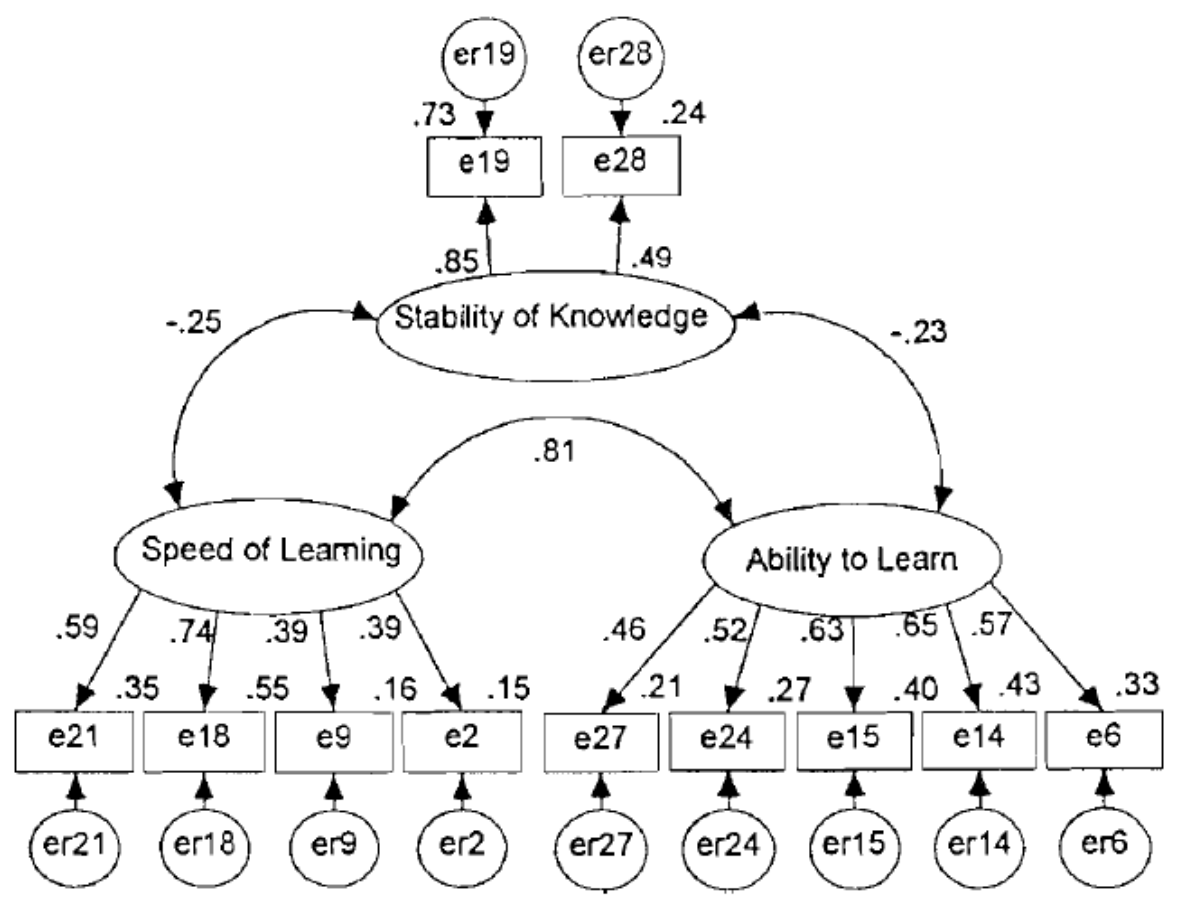

Note. Numbers on the single-headed arrows are factor loadings. Numbers on the double-headed arrows are correlations. Num-bers on the top of rectangles are the variances of the observed variables.

Table 2. Items (and Their Factor Loadings) Retained in the Analysis

\begin{tabular}{lll}
\cline { 3 - 3 } Item & \multicolumn{2}{c}{ Factor loading } \\
\cline { 2 - 4 } & $\begin{array}{c}\text { Speed of } \\
\text { Learning }\end{array}$ & $\begin{array}{c}\text { Ability to } \\
\text { Learn }\end{array}$ Stability of \\
Knowledge
\end{tabular}

If I cannot understand something quickly, it usually means I will never understand it.

If I am ever going to understand something, it will make sense the first time I hear it.

You cannot learn anything more from a tex tbook by reading it twice. $\quad .39$

If I can't understand something right away, I will keep on trying. $\quad .39$

Working hard on a difficult problem only pays off for the really smart students.

.65

.63

.57

Sorne people are just born smar, others are born dumb.

.52 school.

Students who are "average" in school will remain average for the rest of their lives.

.46

Scientists can get to the truth if they just keep searching for it.

If scientists try hard enough, they can find the truth to almost everything. 
Table 3. Zero-Order Correlations Among Scale Items of the Final Three-Factor Measurement Model

\begin{tabular}{|c|c|c|c|c|c|c|c|c|c|c|c|}
\hline Item & 2 & 6 & 9 & 14 & 15 & 18 & 19 & 21 & 24 & 27 & 28 \\
\hline \multicolumn{12}{|l|}{2} \\
\hline 6 & .24 & & & & & & & & & & \\
\hline 9 & .18 & .14 & & & & & & & & & \\
\hline 14 & .21 & .36 & .25 & & & & & & & & \\
\hline 15 & .21 & .40 & .21 & .43 & & & & & & & \\
\hline 18 & .28 & .30 & .30 & .39 & .35 & & & & & & \\
\hline 19 & -.16 & -.13 & -.06 & -.12 & -.06 & -.20 & & & & & \\
\hline 21 & .17 & .25 & .20 & .33 & .34 & .46 & -.04 & & & & \\
\hline 24 & .21 & .31 & .18 & .33 & .31 & .31 & -.14 & .21 & & & \\
\hline 27 & .13 & .27 & .18 & .30 & .25 & .28 & -.18 & .25 & .27 & & \\
\hline 28 & -11 & -.09 & -.05 & -.09 & -.01 & -.08 & .42 & -.07 & -.06 & -.08 & \\
\hline$M$ & 2.02 & 2.05 & 2.04 & 1.97 & 2.05 & 1.88 & 4.00 & 2.27 & 2.32 & 1.96 & 3.51 \\
\hline$S D$ & .99 & 1.29 & 1.14 & 1.15 & 1.21 & 1.11 & 1.03 & 1.12 & 1.31 & 1.07 & 1.09 \\
\hline
\end{tabular}

Note. Item correlations based on the original model are available upon request.

Table 4. Goodness-of-Fit Statistics for the Confirmatory Factor Analyses

\begin{tabular}{lrrrrrrr}
\hline \hline Model & $n$ & $d f$ & \multicolumn{1}{c}{$\chi^{2}$} & $\chi^{2}: d f$ ratio & GFI & CFI & RMR \\
\hline Hypothesized (4 factors) & 650 & 399 & $1,161.49$ & 2.91 & .867 & .670 & .088 \\
Modified (3 factors) & 650 & 41 & 66.19 & 1.61 & .982 & .978 & .038 \\
Replicated (3 factors) & 619 & 41 & 81.43 & 1.98 & .977 & .965 & .044 \\
\hline
\end{tabular}

Note. GFI = goodness-of-fit index; CFI = comparative fit index; RMR = root mean square residual.

Table 5.-Intercorrelations Among Latent Variables

\begin{tabular}{|c|c|c|c|c|c|c|}
\hline \multirow[b]{2}{*}{ Variable } & \multicolumn{3}{|c|}{ Modified model } & \multicolumn{3}{|c|}{ Replicated model } \\
\hline & 1 & 2 & 3 & 1 & 2 & 3 \\
\hline \multicolumn{7}{|l|}{ 1. Certain } \\
\hline 2. Quick & -.34 & & & -.25 & & \\
\hline 3. Fix & -.27 & .96 & & -.23 & .81 & \\
\hline
\end{tabular}

Because students with available GPA scores appeared comparable to the entire sample, we proceeded with the regression analysis. GPA was regressed on grade in school, gender, and the three epistemological belief scores in step-wise regression. At each step of the analysis, the variable accounting for the most variance entered the equation. Two predictor variables were significant: (a) belief in fixed ability; $F(1,356)=28.47, p<.001, b=-.24$, MSE $=.52$; and $(b)$ belief in quick learning, $F(1,356)=8.65, p$ $<.01, b=-.18, \mathrm{MSE}=.51$. The less students believed in fixed ability to learn and quick learning, the better GPA they earned. 


\section{Discussion}

This study provides the first glimpse of middle school students' epistemological beliefs using a multiple-dimension paradigm. Although middle school students' epistemological beliefs appear to be multidimensional, their beliefs seem to have a simpler structure than that found among high school and college students (Schommer, 1990, 1993, 1998). A confirmatory factor analysis of the middle school students' responses to the EB scale demonstrated that the four-factor model obtained with samples of high school and college students (Schommer, 1990, 1994) did not fit the data obtained from the sample of middle school students. A model of three factors did fit the data. That model included beliefs about Ability to Learn, Speed of Learning, and Stability of Knowledge.

The nature, as well as the number, of middle school students' epistemological beliefs differed from older students. Beliefs about learning appeared to be better developed according to the number of items that loaded on each learning factor, perhaps because ideas about knowledge are more abstract than those about learning. Or, from an applied point of view, the early appearance of beliefs about learning also may reflect middle school students' developmental reality: Children spend a lot of time in school intentionally trying to learn. Teachers encourage children to think and talk about their learning. The same is not true of ideas about knowledge.

The finding that learning beliefs appear to be more developed than knowledge beliefs generates a testable hypothesis that beliefs about learning may proceed the development of knowledge beliefs. Epistemological research with adults is consistent with that notion. To test the influence of education and maturation on the development of epistemological beliefs, Schommer (1998) surveyed over 400 adults. One third of the sample had only high school education, another third had some college, and the remaining adults had postgraduate education. After statistically controlling for education, Schommer (1998) found that age predicted growth in beliefs about learning. After statistically controlling for age, level of education predicted growth in beliefs about knowledge. The results suggest that maturation is critical in the development of beliefs about learning. Without formal education however, beliefs about knowledge seem less likely to advance.

Furthermore, the hypothesis that learning beliefs proceed knowledge beliefs opens up the debate as to whether one should consider beliefs about learning as a core aspect of personal epistemology or as supportive beliefs that lead to beliefs about knowledge. Most early epistemological belief researchers (Kitchener \& King, 1981; Perry, 1968) restricted their concept of personal epistemology to the more traditional notion of philosophy and included only beliefs about knowledge, such as the source of knowledge or the justification of knowledge. Schommer (1990) expanded on that conception to include beliefs about the acquisition of knowledge in order to develop a more comprehensive view of personal epistemology.

In a recent review of the literature, Hofer and Pintrich (1997) proposed that the concept of epistemological beliefs should be restricted to beliefs about knowledge per se. That is, they defined epistemological beliefs as beliefs about the structure, certainty, and justification of knowledge. They considered beliefs about learning as peripheral to the core of epistemological beliefs. Learning beliefs may be precur-sors to beliefs about knowledge.

The debate to include or exclude beliefs about learning as part of personal epistemology should not overshadow the more important issue-beliefs about learning and beliefs about knowledge both appear to have a critical impact on learning. In earlier research, belief about intelligence predicted persistence in the face of difficult tasks (Dweck \& Leggett, 1988) and belief in quick learning predicted students' study approaches to mathematical problem solving (Schoenfeld, 1983). In this study, the less students believed in fixed ability and quick learning, the higher GPA they earned. Furthermore, the link to GPA is consistent with previous research using the multidimensional paradigm. The less high school students believe in quick learning, the higher GPA they earn (Schommer, 1993). The less college students 
believe in quick learning and simple knowledge, the better they comprehend complex academic text (Schommer, 1990; Schommer et al., 1992).

This study raises more developmental issues with the finding that beliefs about knowledge were substantially different than those of older students. Specifically, middle school students' beliefs about the stability of knowledge were simplistic compared with adults' beliefs. Also, belief about the structure of knowledge did not emerge. The apparent presence of belief about the stability of knowledge among the middle school students is consistent with Boyes and Chandler's (1992) study of adolescent epistemological development. They found precursors of beliefs about the certainty of knowledge in early adolescence. It was not until late adolescence, during the onset of formal operations, that more clearly defined beliefs about the certainty of knowledge were established.

The apparent absence of a belief about the structure of knowledge in this study requires further investigation for a strong explanation. There are at least two hypotheses to be considered in light of our findings. First, it is possible that the young students in this study had not yet established their metacognitive views that reflect on the structure of knowledge, as assessed in statements such as, "Thinking about what a textbook says is more important than memorizing what a textbook says." Second, the students' classroom exposure to scientific knowledge or historical facts may have provided them with enough cognitive input to begin to develop their thoughts on the stability of knowledge.

The finding that middle school students' epistemological beliefs are correlated generates another testable hypothesis: Middle school students' epistemological beliefs are less differentiated than the beliefs of older students. That hypothesis is consistent with Schommer's (1994) hypothesis that multidimensionality may vary over time with less differentiation evident in the early years.

The idea that conceptual understanding might vary in integration and differentiation is consistent with other developmental theories (Block, 1973). For example, Wellman (1990) theorized that young children have a global theory of the mind. Once children reach adulthood, their theory of the mind becomes differentiated. That is, adults believe that the mind consists of many distinct components, such as perceptions, emotions, intentions, and knowledge (D'Andrade, 1987; Montgomery, 1992).

The study of epistemological beliefs has important implications for practice. It is unclear from any of the research to date whether what is being assessed is students' stable personal epistemology or their response to the context of the classroom. In either case, it is critical to consider how education may contribute to the development of students' epistemological beliefs. If instruction consists of presenting simple, disconnected information or if tests require recall of isolated facts, students can come to at least two different conclusions: (a) instruction and testing reflect the nature of know ledge or (b) instruction and test-ing are merely activities in a game called "school," and there is little relevance to real-world thinking. In the first situation in which students take education at face value, their self-espoused epistemological beliefs are being molded by the education process. In the second situation in which students view school as a game, they are likely to conform to the epistemological demands of their teachers in order to survive academically. Although survival strate-gies are signs of adaptation, that approach to learning leaves the students' knowledge base impoverished and poorly organized. Future research should attempt to answer such questions as: (a) How do students acquire an epistemological belief system? (b) Can students be taught a set of epistemological beliefs that lead to shifts in their classroom performance or attitudes toward learning? (c) How do students' epistemological beliefs compare with those of their teachers?

\section{References}

AMOS 3.6 [Computer Software]. (1997). Chicago, IL: Smallwaters Corporation.

Block, J. H. (1973). Conceptions of sex role: Some cross-cultural and longitudinal perspectives. American Psychologist. 28, 512-526. 
Boyes, C. M., \& Chandler, M. (1992). Cognitive development, epistemic doubt, and identity formation in adolescence, Journal of Youth and Adolescence, 21, 277-303.

D' Andrade, R. (1987). A folk model of the mind. In D. Holland \& N. Quinn (Eds.), Cultural models in language and thought. Cambridge: Cambridge University Press.

Dunkle, M. F., Schraw, G. J., \& Bendixen, L. (1993, April). The relationship between epistemological beliefs, causal attributions, and reflective judgment. Paper presented at the annual meeting of the American Educational Research Association, Atlanta. GA.

Dweck, C. S., \& Leggett, E. L. (1988). A social-cognitive approach to motivation and personality. Psychological Review, 95, 256-273.

Hatcher, L. (1994). A step-by-step approach to using SAS system for factor analysis and structural equation modeling. Cary, NC: SAS Institute.

Hofer, B. K., \& Pintrich, P. R. (1997). The development of epistemological theories: Beliefs about knowledge and knowing and their relation to learning. Journal of Educational Psychology, 67, 88140.

Kardash, C., \& Scholes, R. J. (1996). Effects of preexisting beliefs, epistemological beliefs, and need for cognition on interpretation of controver-sial issues. Journal of Educational Psychology, 88, 260271.

Kitchener, K. S., \& King, P. M. (1981). Reflective judgment: Concepts of justification and their relationship to age and education. Journal of Applied Developmental Psychology, 2, 89-116.

Montgomery, D. E. (1992). Young children's theory of knowing: The development of a folk epistemology. Developmental Review, 12, 410-430.

Mori, Y. (1996). Beliefs about language learning and their relationship to the ability to integrate information from multiple sources in interpreting novel kanji compounds. Unpublished doctoral dissertation, University of Illinois at Urbana-Champaign.

Perry, W. G. Jr. (1968). Patterns of development in thought and values of students in a liberal arts college: A validation of a scheme. Cambridge, MA: Bureau of Study Counsel, Harvard University. (ERIC Document Reproduction Service No. ED 024315)

Schoenfeld, A. H. (1983). Beyond the purely cognitive: Beliefs systems, social conditions, and metacognitions as driving forces in intellectual performance. Cognitive Science. 7, 329-363.

Schommer, M. (1990). Effects of beliefs about the nature of knowledge on comprehension. Journal of Educational Psychology, 82, 498-504. Schommer, M. (1993). Epistemological development and academic performance among secondary students. Journal of Educational Psychology, 85, 1-6.

Schommer, M. (1994). An emerging conceptualization of epistemological beliefs and their role in learning. In R. Garner \& P. Alexander (Eds.), Beliefs about text and about text instruction (pp. 25-39). Hillsdale, NJ: Erlbaum.

Schommer. M. (I 998). The influence of age and education on epistemo-logical beliefs. The British Journal of Educational Psychology, 68, 551-562.

Schommer, M., Crouse, A., \& Rhodes, N. (1992). Epistemological beliefs and mathematical text comprehension: Believing it's simple doesn't make it so. Journal of Educational Psychology, 84, 435-443. Wellman, H. M. (1990). The child's theory of the mind. Cambridge, MA: Bradford/MIT Press. 